Originally submitted to Additive Manufacturing on 22/10/2018

Revised manuscript resubmitted to Additive Manufacturing on 12/02/2019

\title{
Design against Distortion for Additive Manufacturing
}

\author{
Anas Yaghi(a), Sabino Ayvar-Soberanis ${ }^{(\mathrm{b})}$, Shanmukha Moturu $^{(\mathrm{c})}, \operatorname{Ravi~Bilkhu}^{(\mathrm{b})}$, Shukri Afazov $^{(\mathrm{a})}$ \\ (a) Manufacturing Technology Centre (MTC); (b) Advanced Manufacturing Research Centre (AMRC); \\ (c) Advanced Forming Research Centre (AFRC)
}

Anas Yaghi (corresponding author) Sabino Ayvar-Soberanis

Shanmukha Moturu

Ravi Bilkhu

Shukri Afazov anas.yaghi@the-mtc.org s.ayvar@sheffield.ac.uk

shanmukha.moturu@strath.ac.uk

r.bilkhu@sheffield.ac.uk

shukri.afazov@the-mtc.org
$+442476701726$

+441142227685

+441415345637

+441142227685

$+442476701689$

\begin{abstract}
This paper presents the methodology and findings of a novel piece of research with the purpose of understanding and mitigating distortion caused by the combined processes of additive manufacturing (AM) and post machining to final specifications. The research work started with the AM building of a stainless steel 316L industrial impeller that was then machined by removing around $0.5 \mathrm{~mm}$ from certain surfaces of the impeller's blades and hub. Distortion and residual stresses were experimentally measured.

The manufacture of the impeller by AM and then machining was numerically simulated by applying the finite element (FE) method. Distortion and residual stresses were simulated and validated. The FE distortion was then used in a numerical procedure to reverse distortion directions in order to produce a new impeller with mitigated distortion. The results have shown that distortions in the new impeller, on average, have reduced to less than 50\% of the original non-compensated values.
\end{abstract}

\section{Keywords}

Additive Manufacturing; Laser Powder Bed Fusion (L-PBF); Finite Element (FE) Modelling; Distortion Compensation and Mitigation; Residual Stress Simulation. 


\section{Introduction}

Additive manufacturing (AM) is pushing towards industrial applications. It is now possible to 3D print components directly with complex features with the advantage of minimising the need for post-processing operations before reaching the desired net shape. Hence, AM is introducing additional benefits to the manufacturing process with nearly unlimited freedom of design.

Unfortunately, residual stress and distortion issues are some of the challenges during the production of AM parts and post machining. Distortion in AM parts is a significant problem in terms of recurring cost and waste of material and can impose an adverse impact on the environment. Numerical modelling allows foreseeing distortion issues and taking corrective measures. These corrective measures are not often taken until a design is already in production.

In general, AM can be modelled with the finite element (FE) method by either following the thermo-mechanical approach or by adopting the inherent strain method [1]. The thermo-mechanical approach can comprise a classic FE thermal analysis or can be based on an analytical temperature field [2], leading to the calculation of residual stresses and distortion. The thermo-mechanical approach, in either case, requires the numerical modelling approximation of "lumping" layers together in order to complete a simulation without involving prohibitively large FE models [3]. Roberts et al [4] have modelled a moving heat source to predict temperature and residual stresses at the micro-scale. The main barrier for this approach is the computational time that is required. Research has been conducted to speed up this approach by using dynamic adaptive meshes where the mesh is refined around the heat source and coarsened elsewhere. The dynamic adaptive mesh refinement technique using a moving heat source has been researched by Martukanitz et al [5] and Patil at al. [6] and implemented in commercial software tools. Despite the speed up, the computational effort at macro-scale remains a challenge.

The inherent strain method, on the other hand, ignores the temperature evolution altogether and assumes a value of plastic strain corresponding to the anticipated thermal strain in each of the Cartesian directions at the inception of cooling from the melting temperature. As the inherent strain is prescribed in an FE model independently of temperature, the complete AM simulation is virtually performed at room temperature, substantially improving the efficiency of the FE model. Due to the improved efficiency of simulating thermo-mechanical processes by adopting the inherent strain method, prior to the application in AM, this method was used to model the process of fusion welding of large structures [7]. Further, Pursell [8] and Keller et al [9] used the inherent strain approach at the macro-scale in their research to model the process of AM, and they implemented the method in commercial tools as well. Fransen [10] uses the inherent strain method to numerically predict residual stresses and distortion in a 3D analysis of a selective laser melting (SLM) component produced by AM. He explains the advantages of using the inherent strain method after describing simulation methods such as the melting pool scale in contrast to the layer-by-layer modelling approach. Li et al [11] describe the modelling of SLM by applying the inherent strain method to four different scanning strategies, validating their numerical work against experimental results. Setien et al [12] also applied the inherent strain method to simulate distortion in an AM component, highlighting the high efficiency that can be achieved by such an approach. Liang et al [13] numerically simulated distortion in depositions of a single wall and a rectangular contour wall models with different number of layers deposited by a representative directed energy deposition (DED) process. They validated their predictions against experimental distortion measurements.

The reported project has developed a means to take corrective action during part design for AM, in particular for laser powder bed fusion (L-PBF) and machining. This means having a numerical tool for holistic distortion compensation, taking into account distortion due to both AM as well as post machining, resulting in a finished component with mitigated final distortion. This has not previously been achieved and reported on in literature. Therefore, the main contribution of this paper is to provide understanding of how distortion can be mitigated for AM followed by post machining. The novelty lies in the development and validation of numerical models for distortion prediction and compensation in AM, followed by post machining.

In the reported work, the application of virtual models for holistic distortion mitigation has been demonstrated and assessed with the feasibility of fabricating a representative industrial impeller. Generally, metallic components used in industrial applications are machined from bulk-rolled or extruded products of a specific alloy. In this project, L-PBF has been applied to produce a stainless steel 316L impeller, which has then been finish-machined. This has been done alongside virtual models to guide the manufacturing for mitigating the risk of high distortion.

The reported work comprised three main stages. In the first stage, the first AM build was produced at the MTC, which included two identical impellers. One impeller was sent to the AMRC, where distortion measurement and post-process machining were carried out. The other identical impeller was sent to the AFRC for residual stress measurement. During the second stage, the FE procedure for reversing distortion at the design phase was created and analysed, which led to the third stage of producing another AM build, which included an impeller with 
compensated-distortion. The compensated-distortion impeller was then sent to the AMRC to be machined and measured for assessing the mitigated distortion.

The main contribution of the reported work is to create a methodology to compensate for the combined distortion induced by both AM and post-process machining. In order to achieve this, distortion induced by AM has had to be investigated, distortion induced by post-process milling has also had to be quantified, and finally the combined distortion has been quantified and compensated for in a newly-produced impeller.

\section{Initial Distortion-Non-Compensated Impellers}

The experimental setup and method as well as the results of the first stage of the project are presented in this section.

\subsection{AM Build}

The first AM build (Fig. 1) included two identical impellers and two miniature bridges (for calibration of the FE AM model). Each miniature bridge was $112 \mathrm{~mm}$ in length, $10 \mathrm{~mm}$ in width and $10 \mathrm{~mm}$ in height [2]. The vertical height of each impeller was $48.6 \mathrm{~mm}$, and the large diameter at the bottom of each impeller was $109 \mathrm{~mm}$.

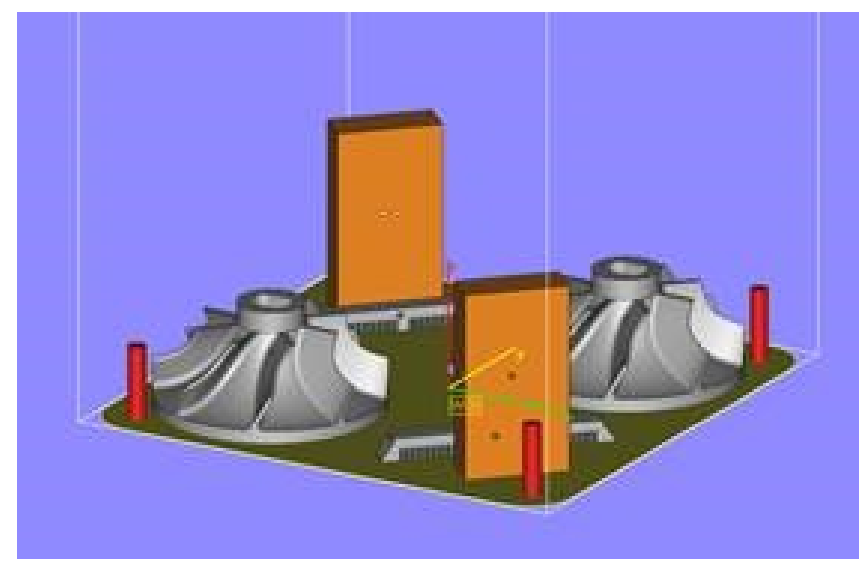

Fig. 1 First additive manufacturing (AM) build

The metallic powder used to manufacture the impellers and calibration specimens throughout the project was stainless steel 316L. The choice of material was made because of the wide industrial availability and range of applications of the material. The project, however, could have been carried out just as well using another metal.

During the AM process, the baseplate (substrate) was preheated to $170 \square \mathrm{C}$, which is the maximum possible preheat temperature for the baseplate in the Renishaw AM250 machine. This preheating was applied to all the manufactured impellers in order to reduce the risk of the impeller cracking away from the baseplate during manufacture. The AM build was produced with consecutive layers of $50 \mu \mathrm{m}$ in thickness in a closed chamber full of argon gas. The complete build took 54 hours and 15 minutes of manufacturing time. Due to the geometry of the impeller, there was no support structure required for its manufacture.

When the AM procedure was completed, the build was taken out of the AM chamber after room temperature had been reached, and the substrate on which the build was laid was then removed using wire electric discharge machining (WEDM), bringing the height of the impeller to $48.6 \mathrm{~mm}$. Distortion measurements and post-machining were conducted at the AMRC for one of the impellers whereas residual stress measurements were conducted at the AFRC for the other identical impeller.

\subsection{Machining}

The machining (milling) of the impeller was done on a Mori Seiki NMV800 machine. A fixture was also prepared, which consisted of a block, cylindrical vice and pre-machined jaws. See details of the fixture and impeller in Fig. 2. The fixture was used to ensure that the component was correctly clamped and centred on the rotatory table of the computer numeric control (CNC) machine. 


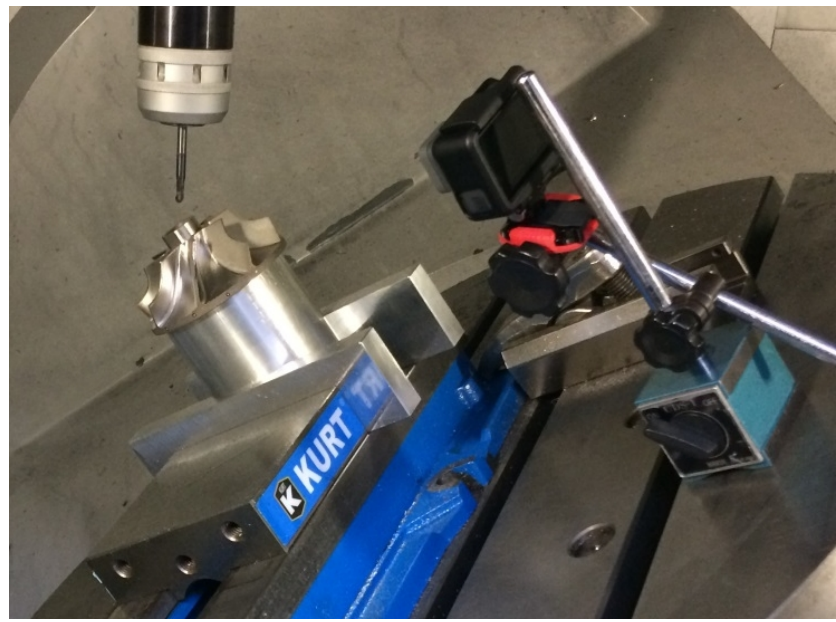

Fig. 2 Impeller directly mounted in the fixture block

The programmed feed per tooth was $0.15 \mathrm{~mm}$, and the manual feed override was kept at $80 \%$ throughout all machining operations, giving an effective feed per tooth of $0.12 \mathrm{~mm}$ (the cutting speed was unaffected by that). The feed override was kept at $80 \%$ to keep the cutting forces lower and reduce the amplitude of machining vibration. The cutting speed used throughout all operations was $90 \mathrm{~m} / \mathrm{min}$. Details of the machining sequence for machining each individual blade, blend radius, and hub are shown in Fig. 3. The blades were machined on the underside. The axial and radial depths of cut used for the different areas of the impeller are specified in Table 1.

(a)

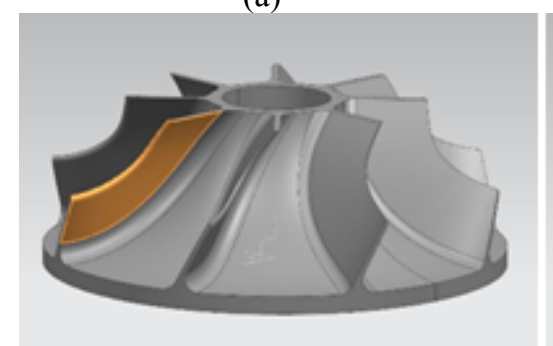

(b)

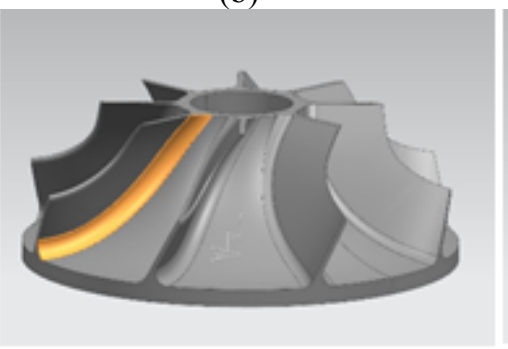

(c)

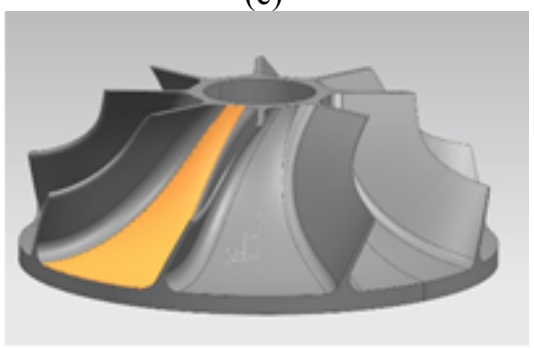

Fig. 3 Details of machining sequence for machining each individual (a) blade, (b) blend radius, (c) hub

Table 1 Axial (ap) and radial (ae) depths of cut used in the machining process

\begin{tabular}{|l|c|c|}
\hline \multicolumn{1}{|c|}{ Area of the impeller } & Roughing & Finishing \\
\hline Blade & ap: $1.2 \mathrm{~mm}-$ ae: $0.4 \mathrm{~mm}$ & ap: $0.14 \mathrm{~mm}-$ ae: $0.1 \mathrm{~mm}$ \\
\hline Blend Radius & ap: $0.4 \mathrm{~mm}-$ ae: $5 \mathrm{~mm}$ & ap: $0.1 \mathrm{~mm}-$ ae: $5 \mathrm{~mm}$ \\
\hline Hub & ap: $0.4 \mathrm{~mm}-$ ae: $1.2 \mathrm{~mm}$ & ap: $0.1 \mathrm{~mm}-$ ae: $0.14 \mathrm{~mm}$ \\
\hline
\end{tabular}

\subsection{Distortion Measurements}

On machine inspection (OMI) probe MP700 was used to monitor the machining process and validate the machining FE model; Fig. 4(a) shows details of three measurement points, coloured in blue, for OMI. The OMI probe was a strain-gauge probe, with a repeatability of $\pm 0.25 \mu \mathrm{m}$; the resolution of the machine tool controller was $0.1 \mu \mathrm{m}$. The measured distortion at the end of machining was approximately $37 \mu \mathrm{m}$ for point $\mathrm{a}, 15 \mu \mathrm{m}$ for point $\mathrm{b}$ and $10 \mu \mathrm{m}$ for point $\mathrm{c}$. Each blade was inspected before and after machining for both roughing and finishing; a full inspection was carried out once all roughing was complete and prior to finish machining. Fig. 4(b) shows the details of the sequence of the blades in the impeller. To investigate the repeatability of the OMI system, a single finished blade (blade 1) was inspected 10 times consecutively at the end of the trials, which indicated an error of less than $3 \mu \mathrm{m}$. 

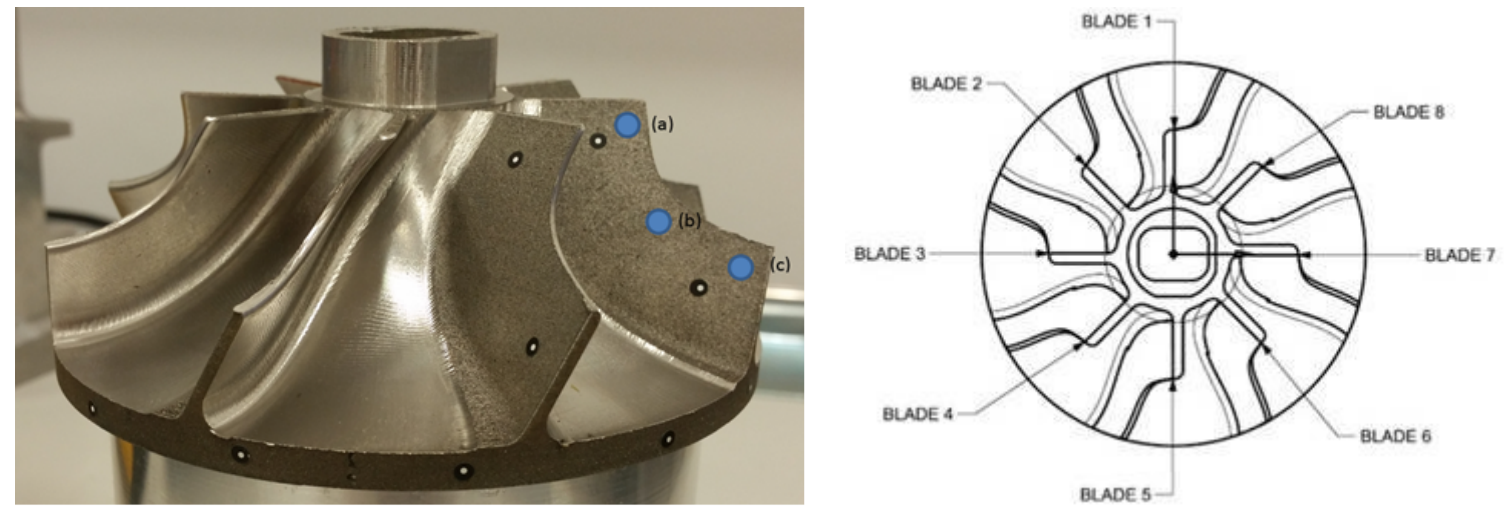

Fig. 4 (a) Measurement points (coloured in blue) for OMI, (b) details of the blade sequence

GOM ATOS triple scan optical measurement system, with MV170 lens, was also used to determine the distortion induced by the AM process as well as at the end of the machining process; the camera resolution is $3296 \mathrm{x} 2472$ pixels, and the MV170 lens/projector set has a measuring volume of 170x130x130mm. The impeller was prepared using chalk dust to prevent any reflections that would influence the results during the scan. Following that, $1.5 \mathrm{~mm}$ reference points were placed on the surface of the blades and the top face of the impeller, as shown in Fig. 5. The optical system created point cloud data of the impeller, which were then used to generate a surface mesh in the stereolithographic (STL) file format.

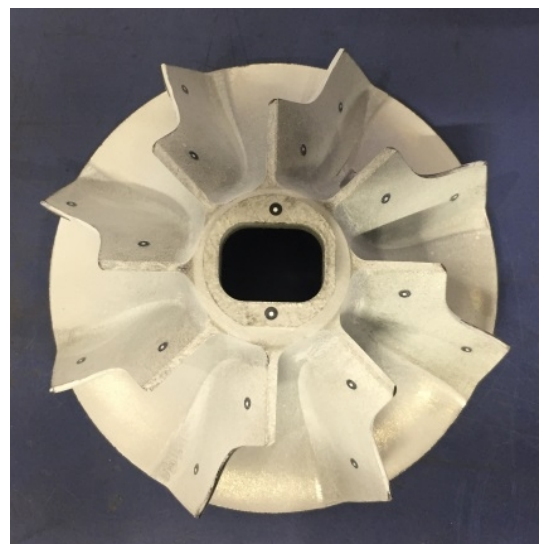

Fig. 5 Impeller prepared for optical measurement

\subsection{Residual Stress Measurements}

Two experimental methods were applied at the AFRC to measure residual stresses of the two initial impellers (non-machined and machined): Electronic Speckle Pattern Interferometry (ESPI) Hole Drilling and the Contour Method.

\subsubsection{Electronic Speckle Pattern Interferometry (ESPI) Hole Drilling}

ESPI is an incremental hole drilling based technique used to measure in plane residual stresses on the surface of a test component to a depth of a few millimetres $(40 \mu \mathrm{m}$ to $1.5 \mathrm{~mm}$ from the surface in this project). Fig. 6 shows the experimental setup of the AM impeller and PRISM system manufactured by StressTech Ltd. The working principle of the ESPI technique is well described elsewhere [1], [2] and [3]. A monochromatic green laser light, with $532 \mathrm{~nm}$ wavelength and $0.8 \& 3.0 \mathrm{~mm}$ carbide coated drills, was used for the residual stress measurements. At each surface incremental drilled hole, a Charge-Coupled Device (CCD) camera was used to record the images and the corresponding surface displacement caused by relaxation of residual stress due to the drilling of the material; the resolution of the CCD camera used for capturing the surface distortion was $1 \mu \mathrm{m}$. 


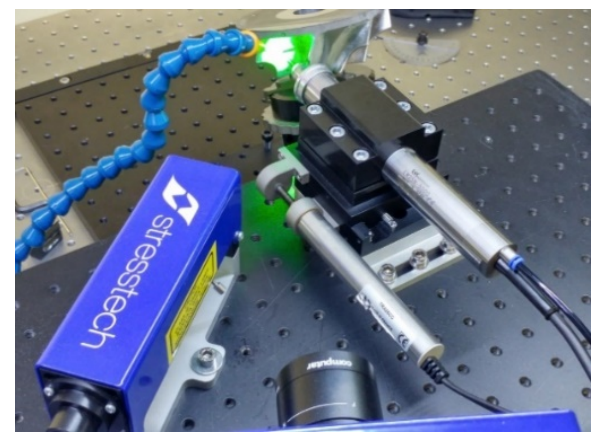

Fig. 6 Experimental setup of the AM impeller and PRISM system

ESPI measurements on the initial AM impeller prior to machining were performed on blade number 3 at three locations (measurement points 1, 2 and 3) on the topside of the blade. Another measurement at the bottom flat surface of the impeller (where WEDM took place) was measured at point 4 (see Fig. 7). Furthermore, ESPI measurements were performed on the initial machined impeller on blades number 2, 4 and 6 at measurement point 2 (starting at the non-machined topside of the blades and piercing through to the machined underside of the blades), as well as on the bottom flat surface of the impeller (where WEDM took place) at two locations, 4 and 5, as shown in Fig. 7. The ESPI measurements for points 4 and 5 were performed vertically from bottom to top using a $3 \mathrm{~mm}$ drill. The measurement of point 2 could not be supported by more points, as drilling had to be normal to the measured surface, and the available space and drill size would not facilitate that.

\section{Top View of Impeller}

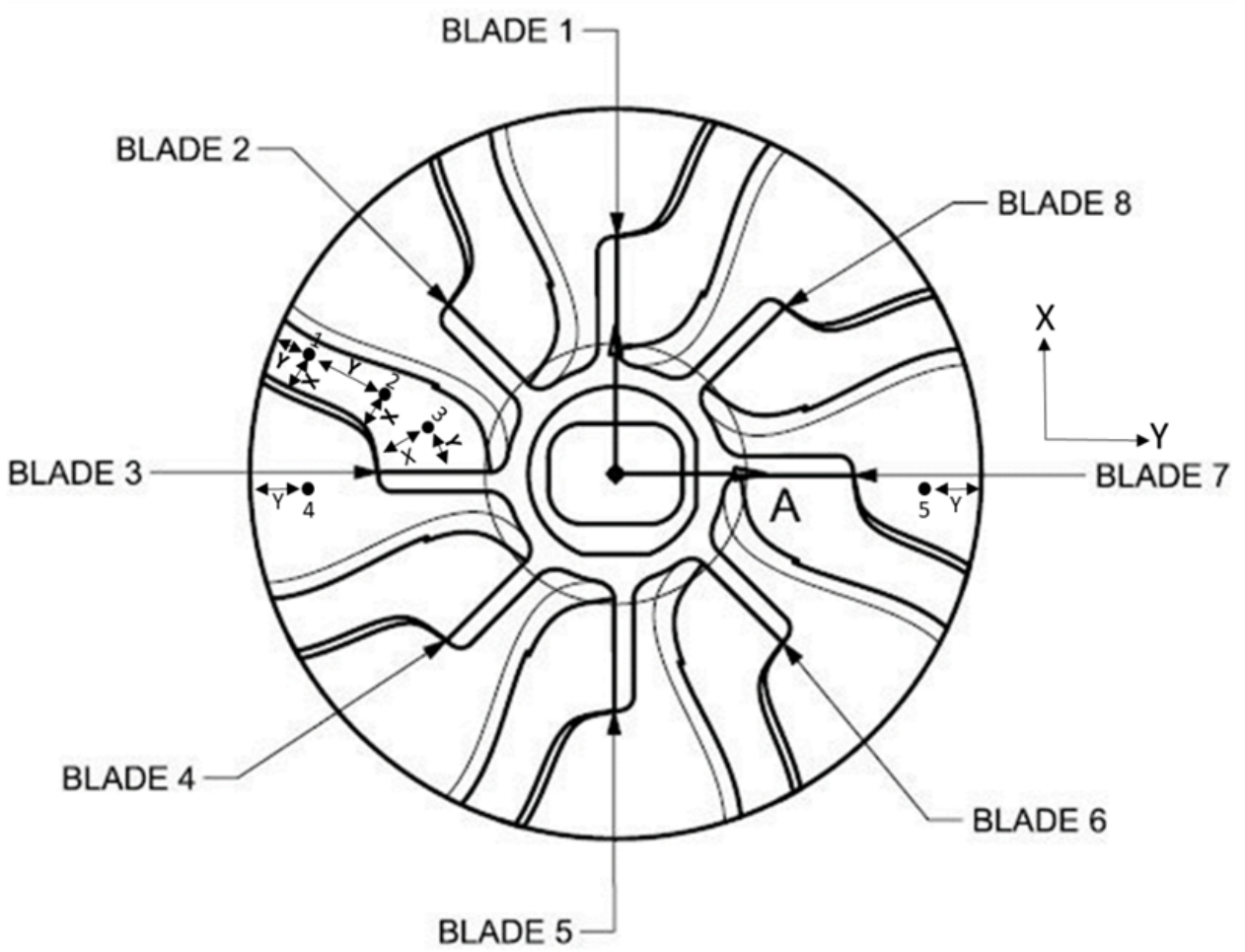

\begin{tabular}{|c|c|c|}
\hline ESPI Measurement Points & $\mathrm{X}$ in $\mathrm{mm}$ & $\mathrm{Y}$ in $\mathrm{mm}$ \\
\hline 1 & 7.36 & 5.36 \\
\hline 2 & 7.39 & 16.26 \\
\hline 3 & 7.58 & 13.24 \\
\hline 4 & - & 12.83 \\
\hline 5 & - & 12.83 \\
\hline
\end{tabular}

Fig. 7 Location of the ESPI measurements

Fig. 8 shows the ESPI residual stress measurement of the initial AM impeller, prior to machining, at points 1,2, 3 and 4. From the results, it can be seen that the peak stress values are concentrated at the surface of the blades 
and generally decrease in magnitude inside the blade away from the free surface. A peak maximum principal stress value of $560 \mathrm{MPa}$ was measured at point 3 , which is on the surface of blade number 3 of the impeller.

(a)

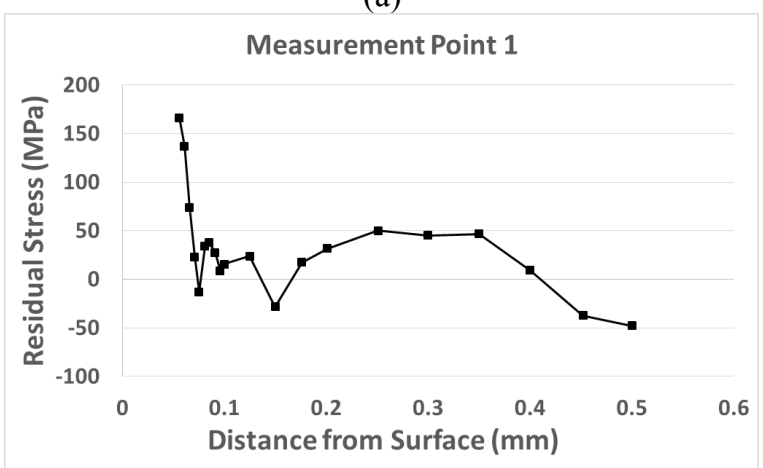

(c)

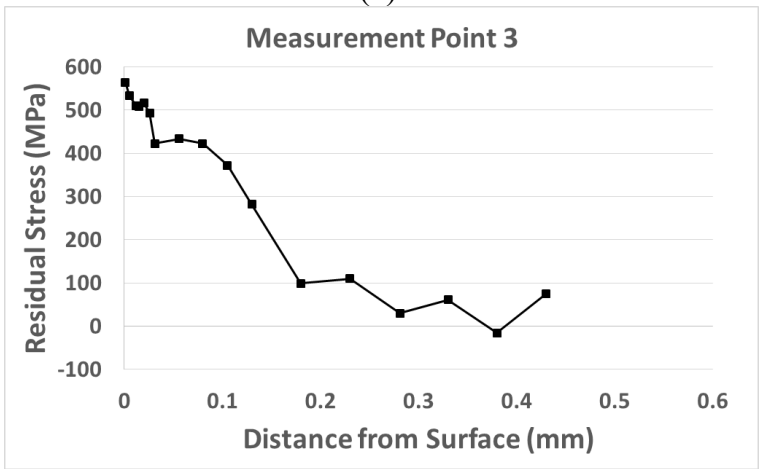

(b)

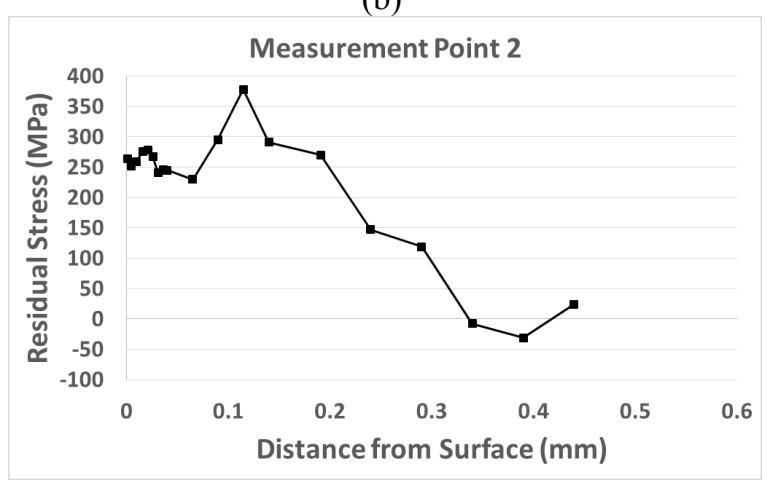

(d)

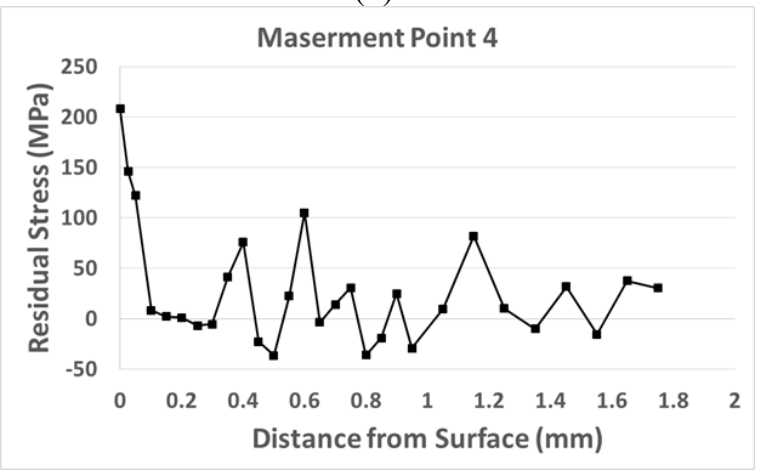

Fig. 8 Residual stress in AM impeller before machining using ESPI

Fig. 9 shows the ESPI residual stress measurement of the machined initial impeller at point 2 for blades 2, 4 and 6 , and also at points 4 and 5 for the bottom flat surface of the impeller. From the results, it can be seen that, in blades 2 and 4 , at depth $\sim 1.5 \mathrm{~mm}$, as the machined surface is approached, maximum principal stresses go from compressive to tensile (from around $-400 \mathrm{MPa}$ to $+275 \mathrm{MPa}$ for Point 2 of Blade 2 and from $-550 \mathrm{MPa}$ to almost $+200 \mathrm{MPa}$ for Point 2 of Blade 4).

\subsubsection{The Contour Method}

The Contour Method is a destructive residual stress measurement method. One of the main advantages of this technique is that it is capable of measuring out-of-plane bulk residual stresses across the sectional profile of a component in a short time. When a specimen is sectioned into two equal parts, the stress relaxation due to WEDM distorts the cut surface. Measuring the crest and trough of the cut surface will provide the displacement due the relaxation of stress. By applying the FE method, the measured distortion is used for predicating the residual stress by applying the necessary force to return the cut surface to its original flat shape (i.e. before cutting) [4].

In the reported work, the specimen was clamped to a WEDM sample stage to minimize the displacement of the component during cutting. The WEDM wire of $0.5 \mathrm{~mm}$ was used for cross sectioning the component into two halves along the YZ plane (between blades 3 and 7). The Coordinate Measurement Machine (CMM) measurements were performed on the cut surface for displacement measurement. Fig. 10 shows the predicted outof-plane residual stress in one of the quadrants of the impeller before machining. Tensile stresses ( $\sim 0$ to $320 \mathrm{MPa}$ depending on location) are concentrated at the surface of the component and compressive stresses ( $\sim 0$ to $-210 \mathrm{MPa})$ are concentrated in the middle of the impeller. Experimentally-measured residual stresses will be compared to corresponding FE predicted residual stresses in the following section. 
(a)

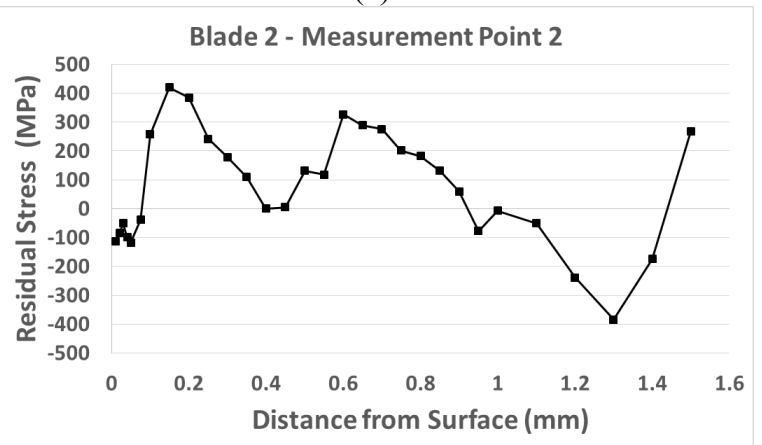

(c)

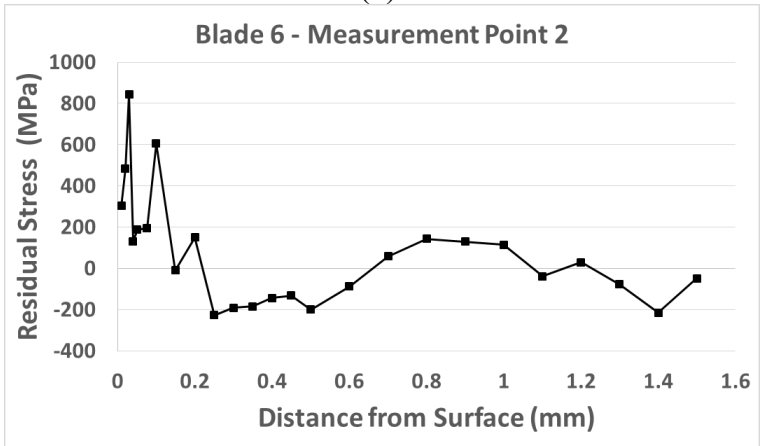

(b)

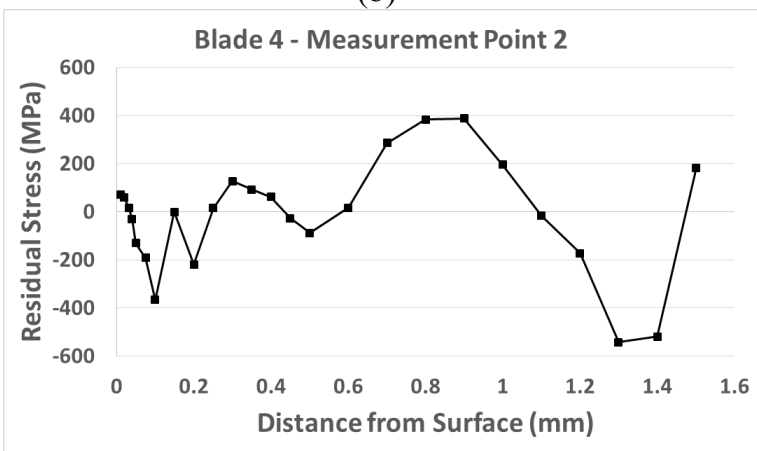

(d)

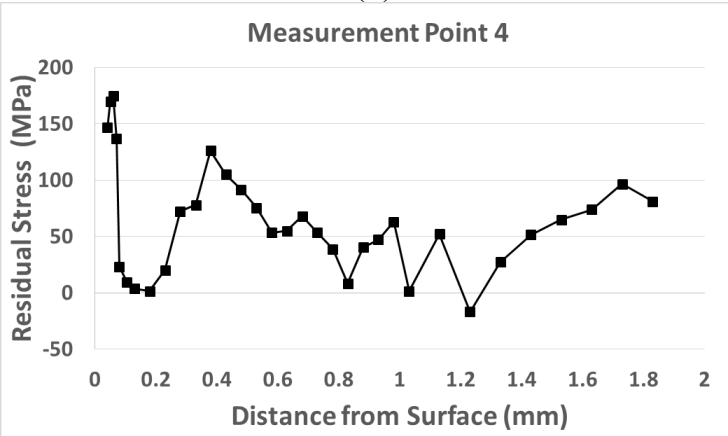

(e)

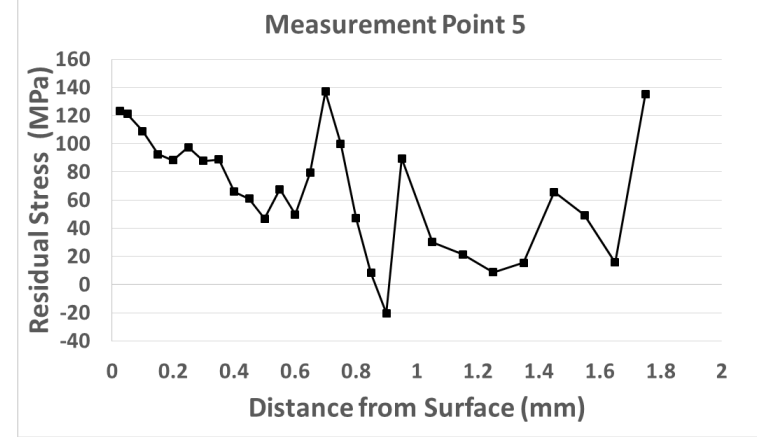

Fig. 9 Residual maximum principal stress in AM impeller after machining using ESPI
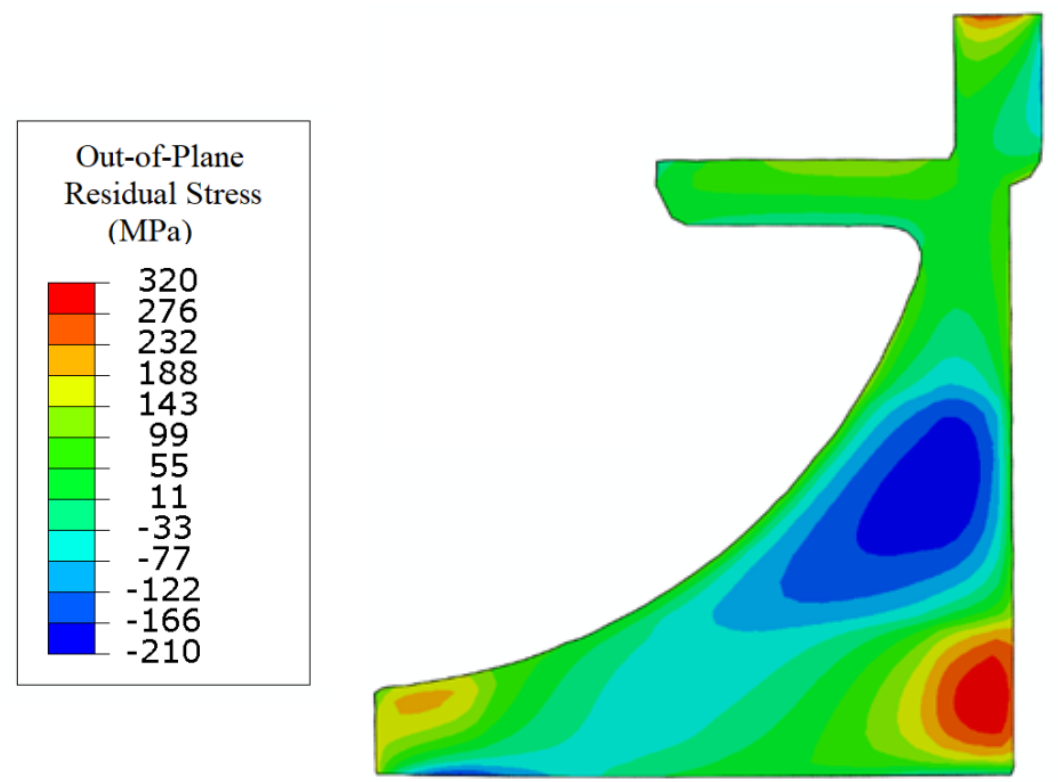

Fig. 10 Residual stresses in the AM impeller before machining using the Contour Method 


\subsection{Numerical Modelling Method}

The numerical modelling method and results for the AM build of the impeller are described in this section.

\subsubsection{Numerical modelling of the AM build}

The AM build of the impeller was numerically simulated by generating an FE model of the impeller using the commercial software package ABAQUS [5] and adopting the inherent strain approach [6]. The FE mesh of the impeller, containing 278,189 nodes and 1,545,915 linear elements, can be seen in Fig. 11. The FE model at the start of the simulation included a mild steel baseplate (substrate), as can be seen in Fig. 11(b), with the dimensions of $248 \mathrm{~mm} \times 248 \mathrm{~mm} \times 40 \mathrm{~mm}$ thick.

(a)

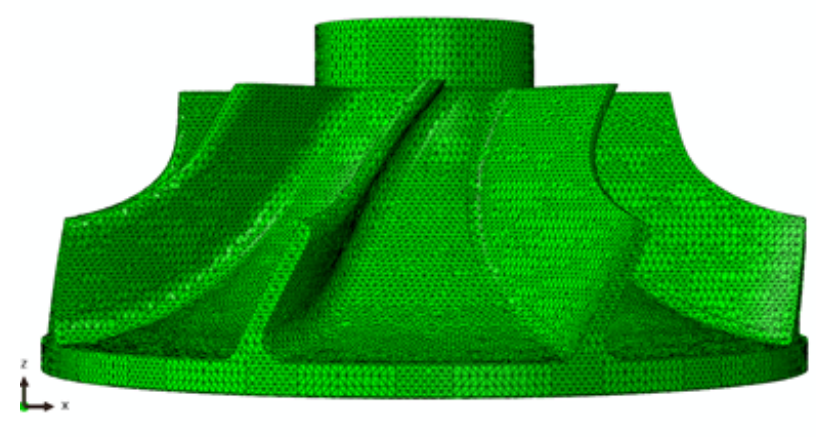

(b)

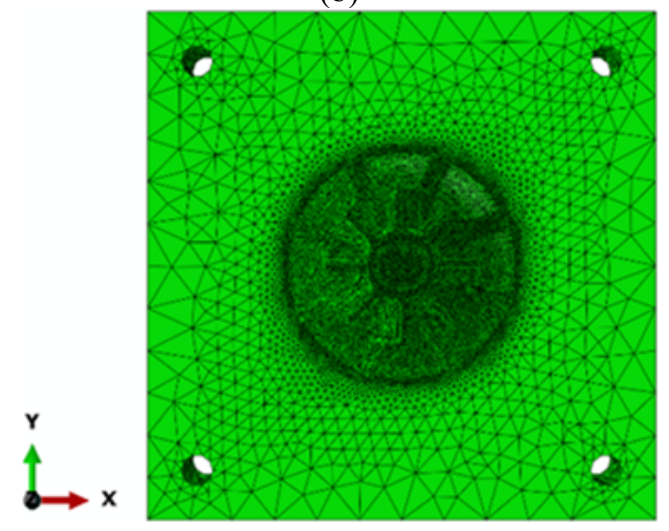

Fig. 11 (a) Finite element (FE) Mesh of the impeller, and (b) Plan view of the impeller on its baseplate (substrate) before removal

The numerical simulation was conducted by sectioning the impeller into 40 layers with equal thickness and activating them consecutively from bottom to top to model the actual building up of the impeller. One inevitable simplification was that the layers being activated in the FE model $(1.24 \mathrm{~mm}$ each) were much thicker than the layers being melted in the real impeller $(50 \mu \mathrm{m}$ each) during AM. That simplification was necessary to prevent the FE model becoming prohibitively large, hence the need for calibration of the FE model. It is worth noting that the 40 layers were sliced into discrete sections in ABAQUS (with each section split by a datum plane); then the sections were meshed with tetrahedral elements, guaranteeing that each section has a discrete number of elements, with no elements crossing over from one section into another.

The miniature bridges were also machined off the baseplate with WEDM and their vertical deflection at both ends were experimentally measured using the shadowgraph technique [7] in order to calibrate the FE model. The vertical deflection at each end averaged at a value of $0.85 \mathrm{~mm}$. An FE model of the miniature bridge was generated and the material properties, originally extracted from data sheets published on the Renishaw website [7], were fine-tuned until they predicted the same value of vertical deflection. The same material property values, given in Table 2, were then used for the FE model of the impeller. The inherent strain value used in the simulation was obtained by dividing the yield strength of the material by the Young's modulus, as researched elsewhere [6]. It has been assumed throughout the reported numerical work that the models are all elastic-perfectly plastic.

Table 2 Material Property Values Used in the FE Models

\begin{tabular}{|l|c|}
\hline \multicolumn{1}{|c|}{ Material Property } & Value used in FE model \\
\hline Young's modulus & $180 \mathrm{GPa}$ \\
\hline Yield Strength & $630 \mathrm{MPa}$ \\
\hline Poisson's Ratio & 0.3 \\
\hline Inherent Strain & -0.0035 in all directions \\
\hline
\end{tabular}

\subsection{Numerical Results}

The FE predicted distortion of the impeller due to AM was numerically modelled as shown in Fig. 12. It can be seen from the figure that the tip of the blades is susceptible to distortion more than any other location in the impeller. The FE predicted maximum principal stress due to AM is shown in Fig. 13. It has been observed that significant plasticity occurs in the impeller as the yield strength of the material is exceeded and the metal work hardens as the impeller goes through the AM thermal cycles. 

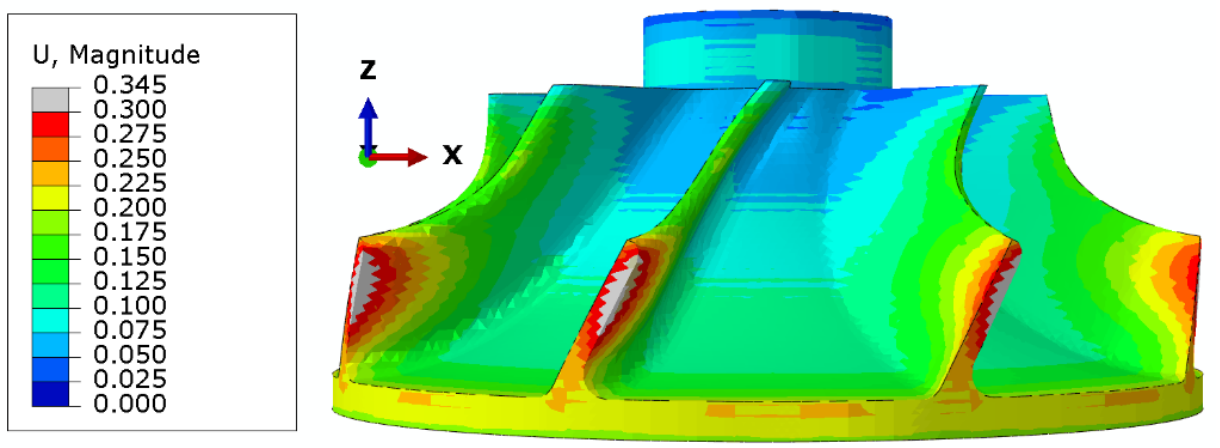

Fig. $12 \mathrm{FE}$ predicted distortion magnitude of the impeller (in $\mathrm{mm}$ ) due to AM (before post-machining)
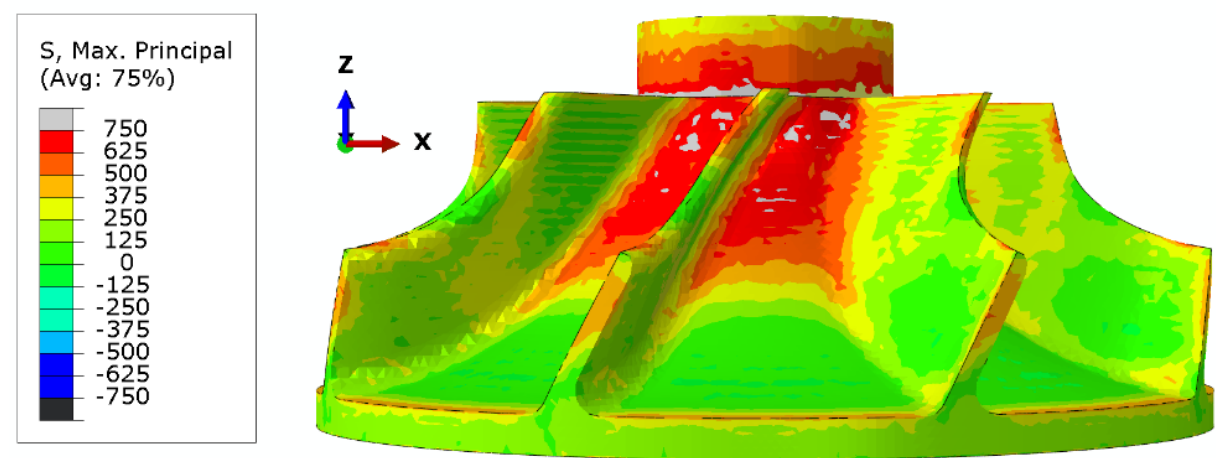

Fig. 13 FE predicted maximum principal stress (in MPa) due to AM (before post-machining)

The FE distortion prediction is validated against GOM scanned data through comparison of distortion results. It can be seen from Fig. 14(b) that the alignment of the impeller is not completely horizontal, resulting in a small non-uniformity of the GOM distortion results in the plan view, which is a typical difficulty during aligning GOM data to the design geometry. It can still be seen, however, that the FE and GOM distortion contours and values are very similar. It is recognised in the reported GOM results that the results are sensitive to the alignment of the impeller when the GOM distortion results are viewed in the used software package. The alignment is dependent on the skill of the user to a certain degree. The alignment in general is guided by the desire to make it as symmetrical as possible. Bearing in mind the small magnitudes of the distortion results, it is a rather challenging task for the user. Bearing this in mind, the GOM results have been used to validate the numerical prediction. The method of distortion compensation, however, was achieved through using the numerical results only.

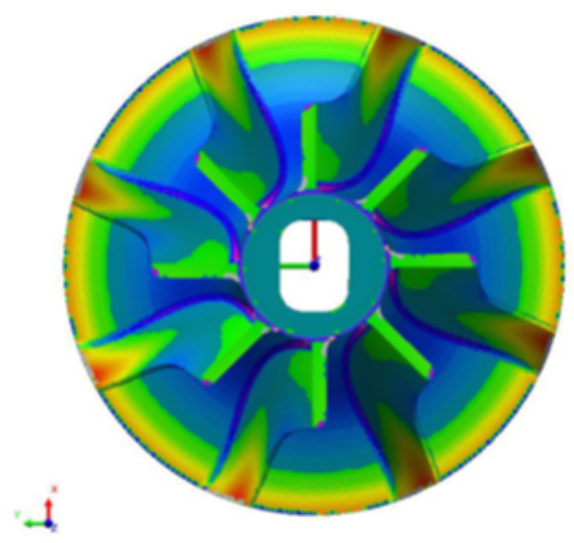

a) FE predicted distortion (in $\mathrm{mm}$ )

+0.200
+0.175
+0.150
+0.125
+0.100
+0.075
+0.050
+0.025
0
-0.025
-0.050
-0.075
-0.100
-0.125
-0.150
-0.175
-0.200

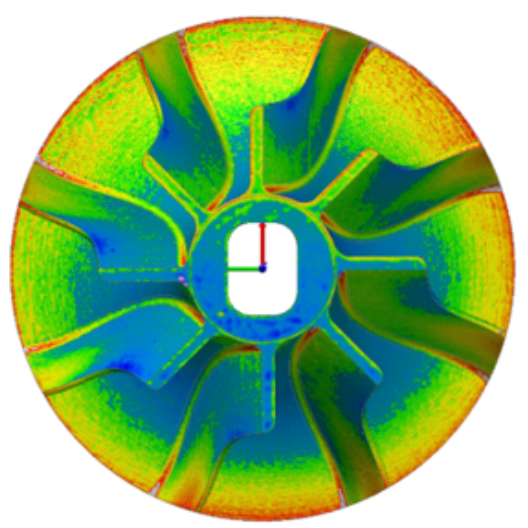

b) GOM scanned distortion (in $\mathrm{mm}$ )

Fig. 14 Comparison of FE predicted distortion with GOM scanned distortion due to AM (before postmachining) 
The FE maximum principal residual stress was compared to corresponding results obtained from ESPI at measurement points 1 and 2 in Fig. 7. The two locations on the FE mesh were pinpointed by selecting 7 nodes on the surface for each location. The corresponding values of maximum principal stress were averaged for each location as shown in Table 3 and compared to those measured by ESPI. It can be seen from the table that the difference between the averaged FE results and ESPI measurements is less than 5\%.

Table 3 Comparison between ESPI measurements and FE averaged values of maximum principal stress

\begin{tabular}{|l|c|c|}
\hline \multirow{2}{*}{ EPSI measurement on surface } & \multicolumn{2}{|c|}{ Maximum Principal Stress (MPa) } \\
\cline { 2 - 3 } & At Point 1 in Fig. 7 & At Point 2 in Fig. 7 \\
\hline \multirow{4}{*}{ Corresponding FE nodal values } & 174 & 264 \\
\cline { 2 - 3 } & 190 & 205 \\
\cline { 2 - 3 } & 212 & 323 \\
\cline { 2 - 3 } & 136 & 325 \\
\cline { 2 - 3 } & 197 & 242 \\
\cline { 2 - 3 } & 152 & 133 \\
\cline { 2 - 3 } & 143 & 262 \\
\hline Averaged FE values over nodes & 196 & 274 \\
\hline
\end{tabular}

In Fig. 15, FE predicted out-of-plane residual stresses due to AM (before machining) are depicted for a crosssection in a quadrant of the impeller. A comparison between these stresses and corresponding experimental residual stresses, measured using the Contour Method, depicted in Fig. 10, generally shows that the FE predicted and experimentally measured residual stresses demonstrate reasonable agreement except at the bottom right corner, where the predicted stresses are lower. This is mainly due to the comparison between the contour method and the FE model not being identical. The predicted stressed are based on a 3D geometrically circumferential model of the impeller, whereas the stresses in the contour method are based on distortion measurement of a cross section applied into a plane strain FE model to calculate the residual stresses. Please note that the residual stress profile, whether experimentally measured or numerically predicted, has been reported herewith after the baseplate had been removed from the impeller. This applies to all the residual stress profiles reported in this paper.
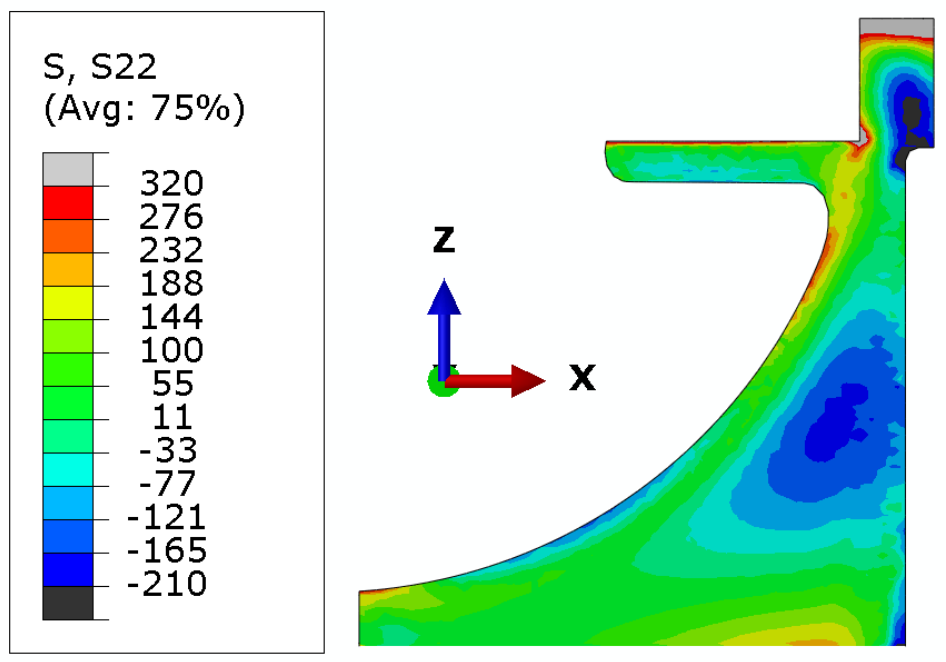

Fig. 15 FE predicted out-of-plane (hoop) residual stress (in MPa) due to AM (before post-machining)

\section{Numerical Distortion-Compensation Procedure}

The method and results of the second stage of the project are presented in this section.

\subsection{Method}

In principle, the distortion-compensation procedure is based on the validated FE distortion prediction. Initially, a surface mesh in the form of an STL file is generated from the original computer aided design (CAD) model of the impeller using a commercial software package such as PolyWorks [8] or Materialise Magics [9]. The FE predicted distortion is then mapped onto the generated surface mesh (STL file), after being given a negative sign, using the open source software package FEDES [10] and [11]. The negative sign allows the surface mesh to distort in the 
opposite direction (at the design stage) in order to compensate for the actual distortion that occurs when the AM process takes place.

Further, if distortion due to post-machining is to be taken into consideration too, machining-induced stresses can be modelled or estimated and then mapped onto the impeller FE model to allow them to relax and influence distortion. Then, the final FE predicted distortion (which includes the effect of AM and post-machining distortion) can be mapped onto the surface mesh, and given a negative sign, to compensate at the design stage for the total distortion induced by both AM and machining. It should be noted that the residual stress profile induced by the process of AM is used as an initial condition for the next stage of the numerical analysis, which is the post-AM milling process; the numerical simulation of the milling process takes the AM residual stress profile as a starting point, superimposing on that stress profile the stresses that are expected to be induced due to the machining process itself, including the stresses due to coming in contact with the machining tool, and then allows the overall stress profile to relax in order to achieve the final residual stress state.

In the reported work, a surface mesh was generated from the original CAD file of the impeller. FE predicted distortion and residual stresses induced by AM were simulated using ABAQUS. Following this, in order to predict distortion due to machining, the following steps were undertaken:

- The residual stress profile induced by the process of AM was used as an initial condition for the simulation of post-process machining.

- The bulk material removal was simulated by mapping residual stresses into an FE mesh, representing the final machined geometry, using FEDES.

- A thin layer of elements $(100 \mu \mathrm{m})$ was modelled in the FE mesh of the impeller, in ABAQUS, to account for surface residual stresses induced by the machining tool.

- Referring to estimated induced stresses due to machining in literature [12], stated to be in the region of $500 \mathrm{MPa}$ at the surface for stainless steel $316 \mathrm{~L}$, a uniform in-plane tensile stress profile of $500 \mathrm{MPa}$ (in both transverse directions to the surface) was mapped onto the modelled $100 \mu \mathrm{m}$ thickness of material in ABAQUS using published mapping techniques [13]; this mapping assumption was validated against OMI distortion, measured at three points, as stated in section 2.3.

- The residual stresses due to AM and the estimated induced stresses due to machining in the FE model were then allowed to relax in ABAQUS and achieve a new state of distortion and residual stresses that took both AM and machining into account.

The final distortion profile was then mapped onto the surface mesh (STL file), in the negative direction, using FEDES, producing a final STL file (pre-distorted) to be used for building another AM impeller with mitigated final distortion.

\subsection{Results}

As described above, distortion-compensation started with a CAD model of the original impeller design. The CAD model was used to produce a volumetric FE mesh in ABAQUS (Fig. 11) as well as a surface mesh (STL file)as shown in Fig. 16.
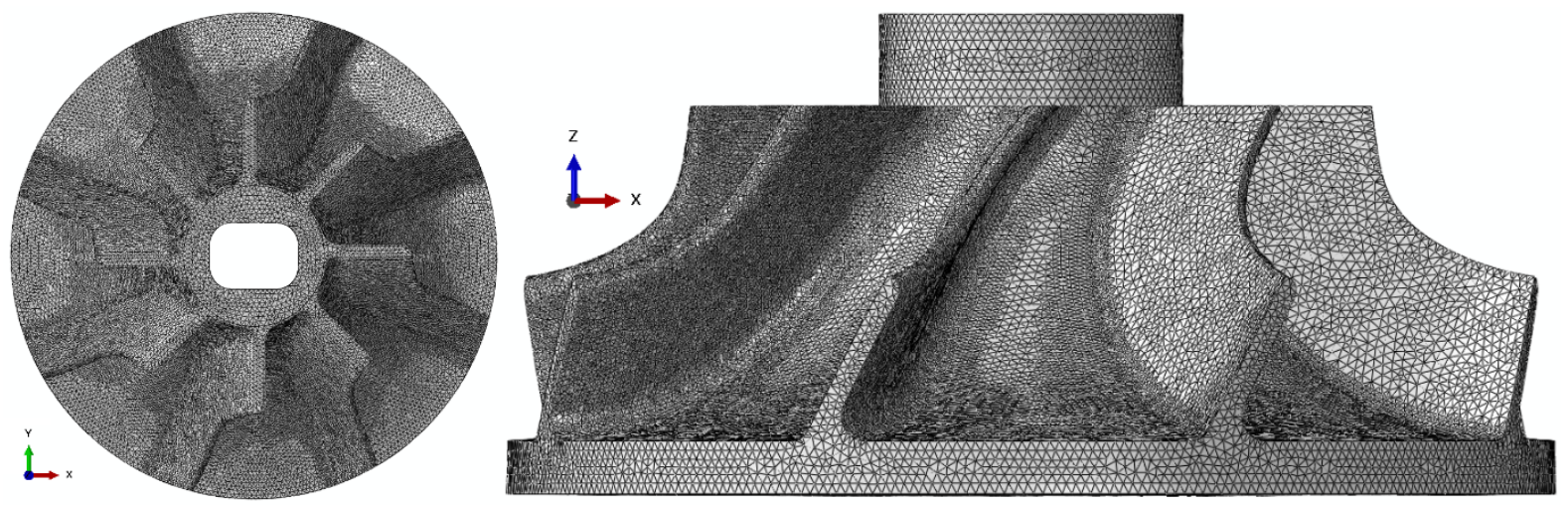

Fig. 16 Surface mesh (STL file) of the impeller produced from the CAD model

The volumetric FE mesh had a thickness of $100 \mu \mathrm{m}$ modelled at locations where post-machining took place, as can be seen in red in the plan and side views in Fig. 17. 

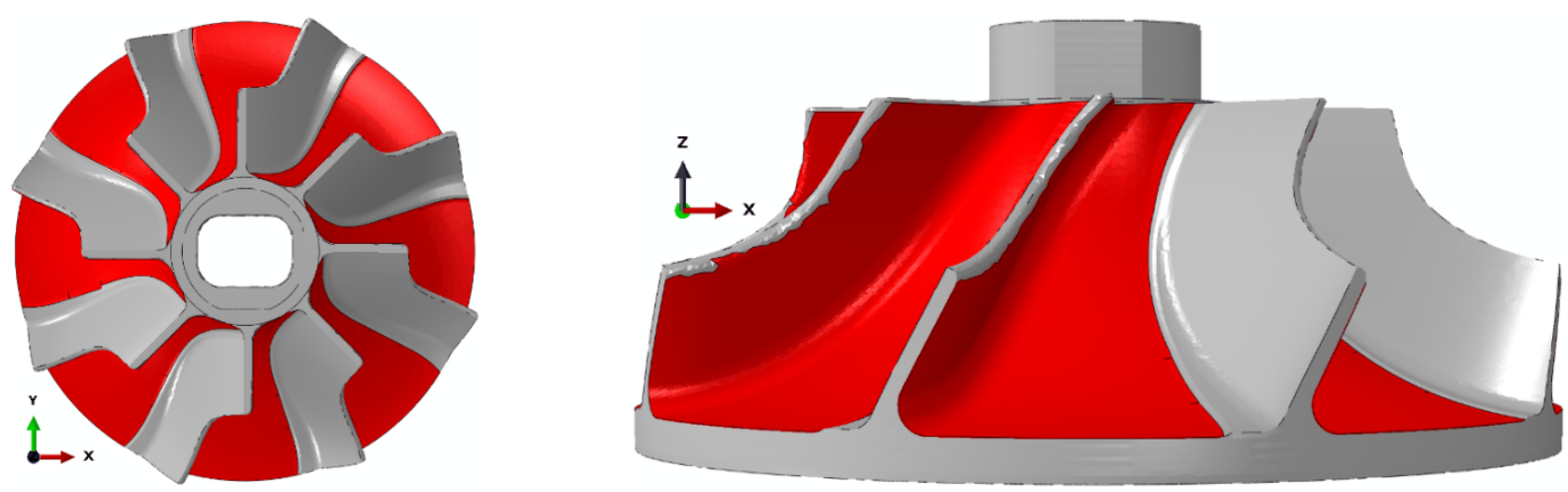

Fig. 17 FE model of the impeller with a layer of $100 \mu \mathrm{m}$ (in RED) to represent post-machining tool-induced stresses

The residual stress profile after all the stresses (due to both AM and machining) had been allowed to relax is shown in Fig. 18. The predicted distortion magnitudes were compared to the OMI measurements at three points of the blade - see Fig. 4(a). The predicted distortion at points a, $\mathrm{b}$ and c were $30 \mu \mathrm{m}, 13 \mu \mathrm{m}$ and $12 \mu \mathrm{m}$ respectively. These predicted distortions showed very good correlation with the OMI measurements in section 2.3; hence, the machining model, including the $100 \mu \mathrm{m}$ layer assumption, can be considered to be valid.
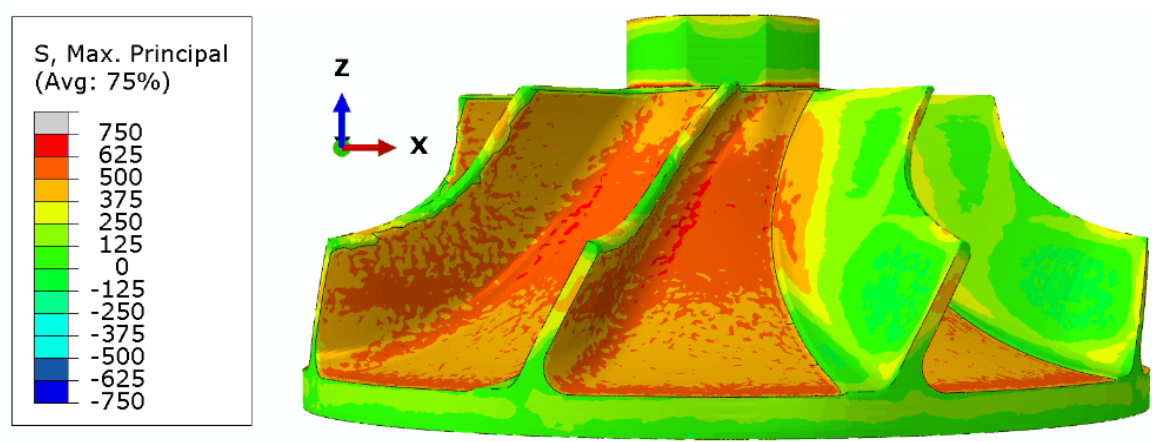

Fig. 18 FE predicted maximum principal stress (in $\mathrm{MPa}$ ) due to both $\mathrm{AM}$ and post-machining

The distortion profile due to both AM and post-machining, shown in Fig. 19, was then used to pre-distort the original STL file in the negative direction and produce a final STL file, shown in Fig. 20, to compensate for the full predicted distortion (due to AM and machining) and manufacture a new impeller with mitigated holistic distortion.

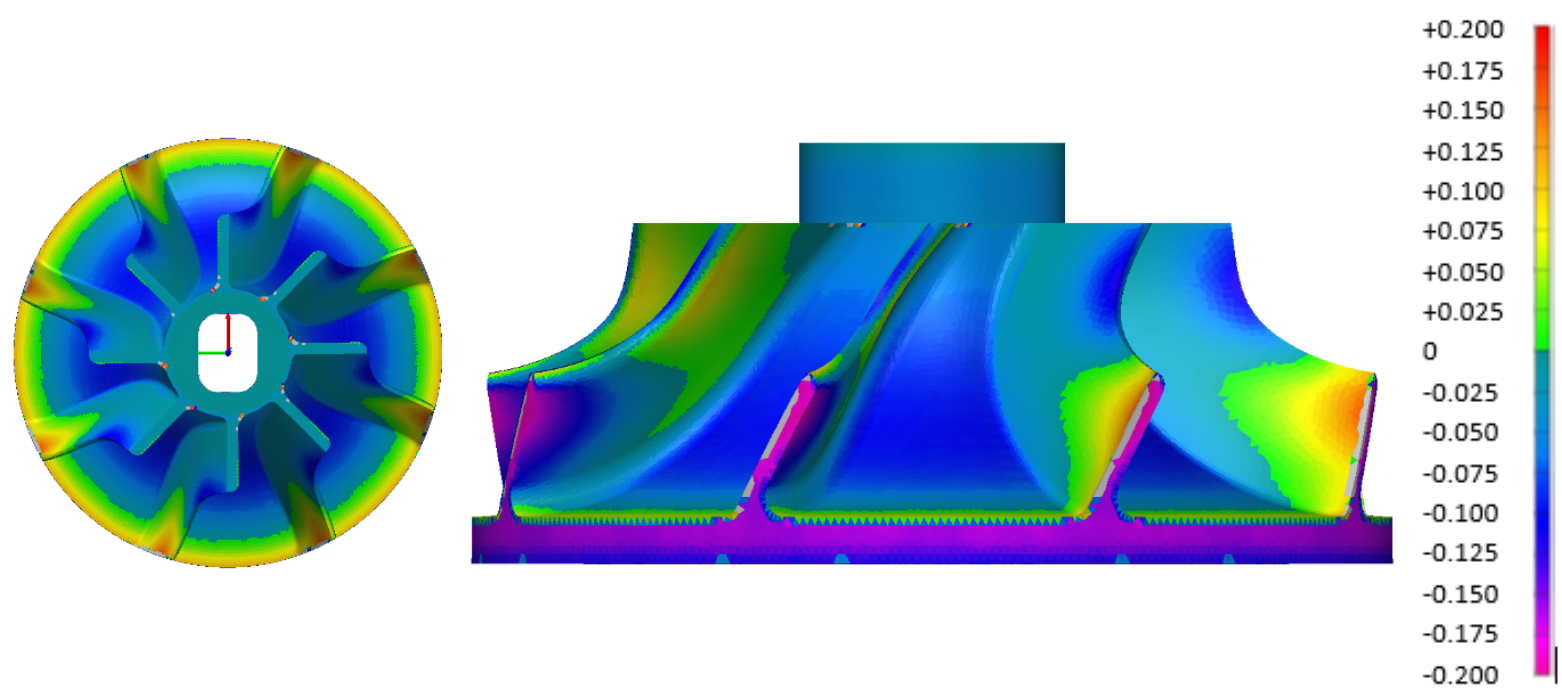

Fig. 19 Distortion profile (in $\mathrm{mm}$ ) due to both AM and post-machining 


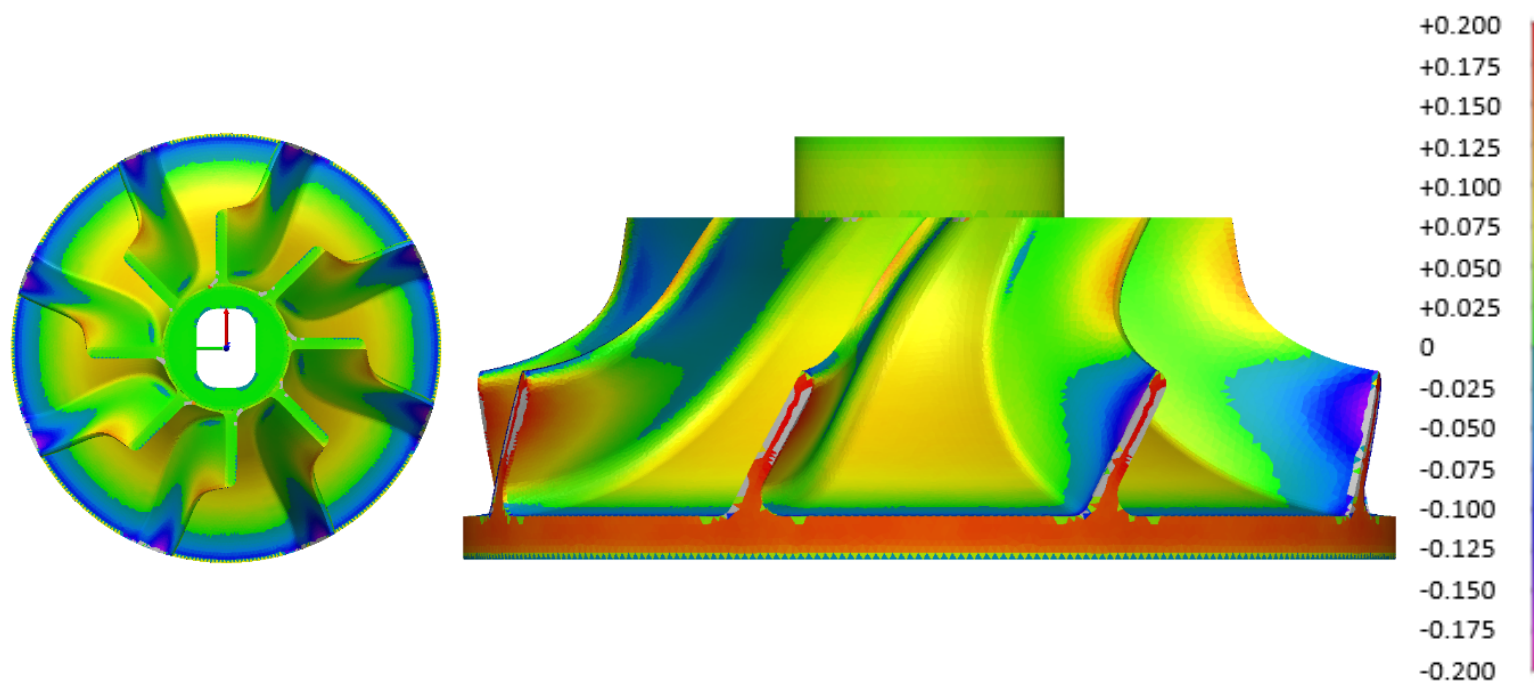

Fig. 20 Pre-distorted (in mm) surface mesh (STL file) used to produce the final impeller with mitigated holistic distortion

\section{Distortion-Compensated AM Build}

The method and results of the compensation stage are presented in this section.

\subsection{Method}

The final impeller was produced in the same way as the initial two impellers with the exception of using a predistorted STL file (depicted in Fig. 20) for the new impeller, in order to mitigate the originally induced distortion due to AM and post-machining.

The new impeller was produced after the distortion-compensation procedure had been executed as described in the previous section (Section 3). The actual AM process was also the same as the procedure of building the initial impellers, described in Section 2. The new impeller was expected to have significantly reduced values of distortion compared to the initial impellers.

\subsection{Results}

The final impeller, with the mitigated distortion, was optically measured after post-machining using the GOM scanning technique. For the purpose of comparing the mitigated distortion with distortion without compensation, the distortion profile due to both AM and machining for the initial impeller is shown first in Fig. 21. Secondly, the mitigated distortion profile (with compensation for holistic distortion) due to both AM and machining, obtained using the pre-distorted STL file (shown in Fig. 20), is depicted in Fig. 22. The distortion scale is shown up to $\pm 0.200 \mathrm{~mm}$ in the figures. Only half of the impeller is shown in the figures and the region of interest is circled in black. Distortion is depicted for two blades in each figure; the blade numbering in the figures is not relevant as the blades in the FE model are identical, and hence the blade numbering for the GOM comparison is also not relevant.

Comparing Fig. 22 with Fig. 21 shows that the holistic distortion peak values have come down from around $200 \mu \mathrm{m}$ to less than $100 \mu \mathrm{m}$. This is a substantial reduction in distortion, leading to improved quality of production in terms of functional performance, reduced risk of scrappage as well as potentially significant cost savings. 

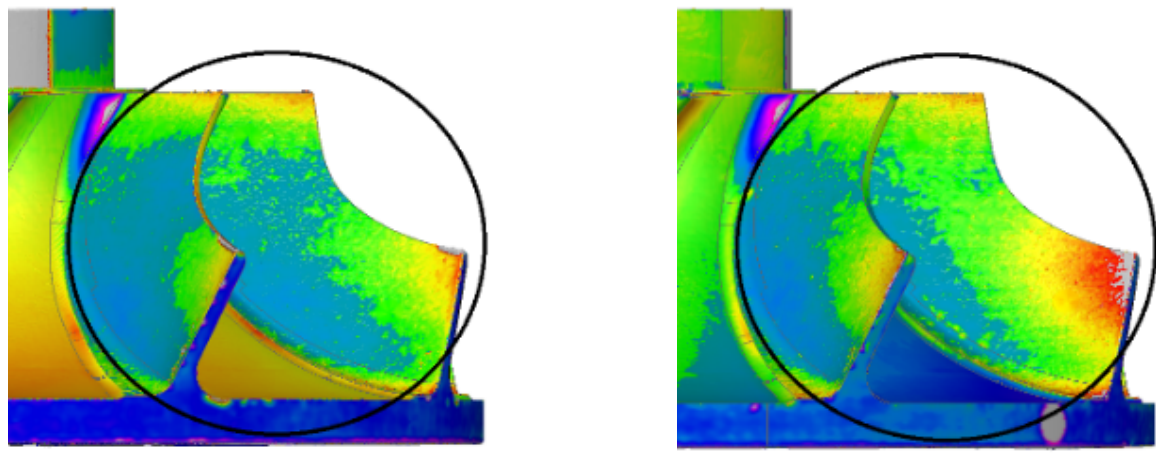

+0.200
+0.175
+0.150
+0.125
+0.100
+0.075
+0.050
+0.025
0
-0.025
-0.050
-0.075
-0.100
-0.125
-0.150
-0.175
-0.200
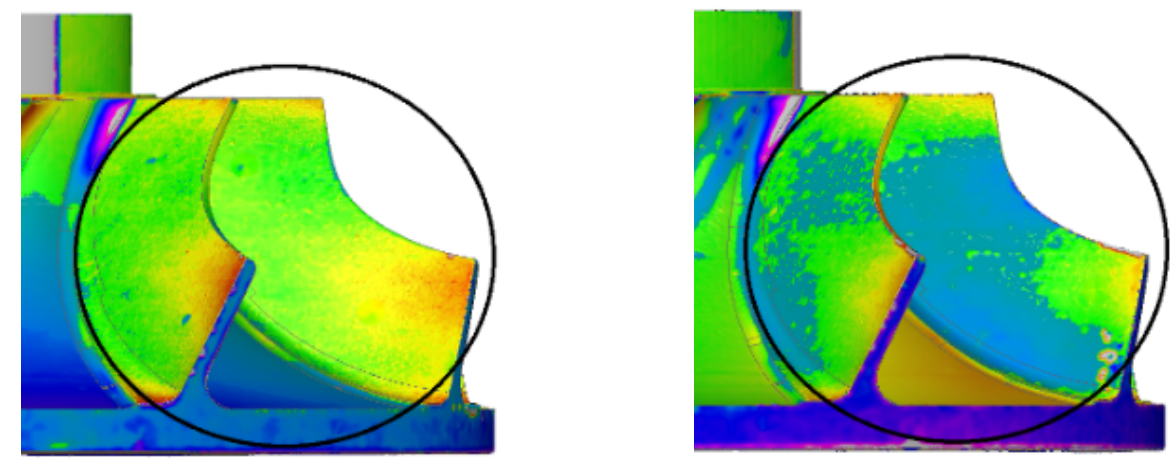

$-0.200$

Fig. 21 Holistic distortion (in $\mathrm{mm}$ ) of the initial impeller (after machining) obtained using GOM scanning
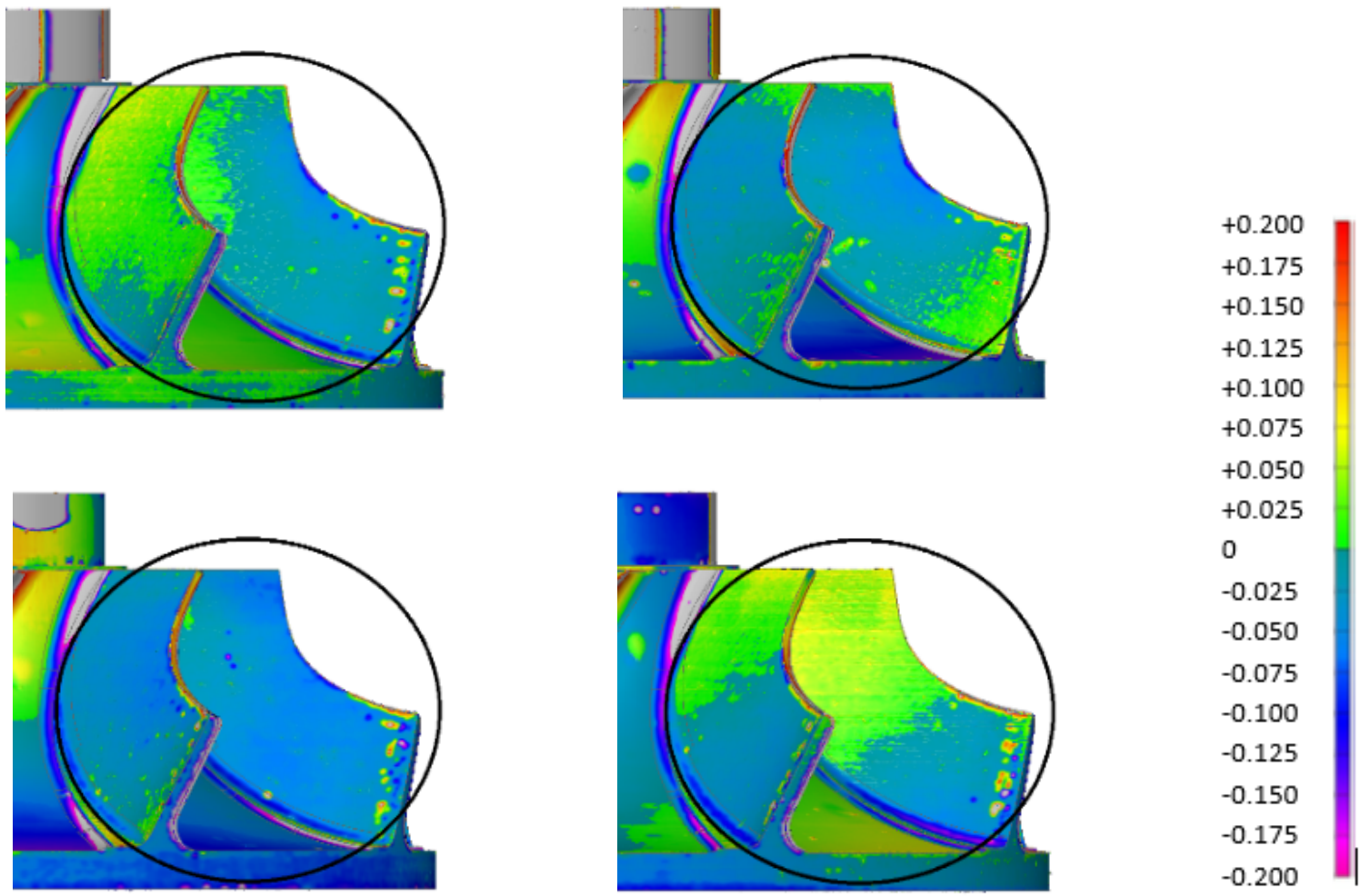

0.200

Fig. 22 Mitigated holistic distortion (in $\mathrm{mm}$ ) of the new impeller (after machining) obtained using GOM scanning 


\section{Conclusions}

- An initial industrial stainless steel 316L impeller was produced by laser powder bed fusion (L-PBF), which is an additive manufacturing (AM) technique, and post machining to final specifications.

- Holistic distortion and residual stresses in the impeller due to both AM and machining were numerically predicted and experimentally measured.

- The numerical predictions, using the finite element (FE) method, were validated by comparing them to the experimental measurements, using the GOM method for measuring distortion as well as Electronic Speckle Pattern Interferometry (ESPI) and the Contour Method for measuring residual stresses.

- The validated FE predicted distortion was then used to compensate for distortion at the design stage by numerical reverse engineering, and a new impeller was produced following the same AM and postmachining procedures, resulting in a distortion-compensated impeller with mitigated distortion.

- The new impeller had peak distortions in its blades that are less than $100 \mu \mathrm{m}$, compared to the peak values in the initial impeller of around $200 \mu \mathrm{m}$, which is a reduction of more than $50 \%$, leading to improved quality of production, reduced risk of scrappage as well as potentially significant cost savings.

\section{Acknowledgements}

The authors wish to acknowledge the High Value Manufacturing (HVM) Catapult for financially funding the project.

\section{References}

[1] A. Yaghi, S. Afazov, A. Holloway and W. Denmark, "COMPARISON OF FAST FINITE ELEMENT MODELLING TECHNIQUES FOR PREDICTION OF DISTORTION AND RESIDUAL STRESSES IN LASER POWDER BED FUSION," in Design and Manufacturing Simulation of Additive Manufacturing, Coventry, UK, 2017.

[2] S. Afazov, A. Yaghi, A. Holloway, W. Denmark, B. Lazaro Toralles and A. Okioga, "Methodology and Validation of Rapid Prediction of Distortion for Powder-Bed Additive Layer Manufacture," in International Conference on Simulation Process and Data Management, Stockholm, Sweden, June 2017.

[3] S. Afazov, W. A. Denmark, B. Lazaro Toralles, A. Holloway and A. Yaghi, "Distortion prediction and compensation in selective laser melting," Additive Manufacturing, vol. 17, pp. 15-22, 110 2017.

[4] I. A. Roberts, C. J. Wang, R. Esterlain, M. Stanford and D. J. Mynors, "A three-dimensional finite element analysis of the temperature field during laser melting of metal powders in additive layer manufacturing," 1. Roberts IA, Wang CJ, Esterlein R, Stanford M, MynorsInternational Journal of Machine Tools \& Manufact, vol. 49, pp. 916-923, 2009.

[5] R. Martukanitz, P. Michaleris, T. Palmer, T. DebRoy, Z.-K. Liu, R. Otis, T. W. Heo and L.-Q. Chen, "Toward an integrated computational system for describing the additive manufacturing process for metallic materials," Additive Manufacturing, Vols. 1-4, pp. 52-63, 2014.

[6] N. Patil, D. Pal, H. K. Rafi, K. Zeng, A. Moreland, A. Hicks, D. Beeler and B. Stucker, "A Generalized Feed Forward Dynamic Adaptive Mesh Refinement and Derefinement Finite Element Framework for Metal Laser Sintering - Part I: Formulation and Algorithm Development," Journal of Manufacturing Science and Engineering, Transactions of the ASME, vol. 137, no. 2, p. Article number 041001, 2015. 
[7] D. Deng, H. Murakawa and W. Liang, "Numerical simulation of welding distortion in large structures," Computer Methods in Applied Mechanics and Engineering, vol. 196, pp. 4613-4627, 2007.

[8] Pursell, "On The Creation of a New Finite Element Simulation Environment for Additive Manufacturing," in NAFEMS Americas Conference: Session Reviews, Session 7/1D, 2016.

[9] N. Keller and V. Ploshikhim, "New method for fast predictions of residual stress and distortion of AM parts," in Annual International Solid Freeform Fabrication Symposium - An Additive Manufacturing Conference, The University of Texas in Austin, USA, 2016.

[10] M. Fransen, Eigenstrain reconstruction of residual stresses induced by selective laser melting, 2016.

[11] C. Li, C. Fu, Y. Guo and F. Fang, "Fast prediction and validation of part distortion in selective laser melting," Procedia Manufacturing, vol. 1, pp. 355-365, 2015.

[12] I. Setien, M. Chiumenti, S. van der Veen, M. San Sebastian, F. Garciandia and A. Echeverria, "Empirical methodology to determine inherent strains in additive manufacturing," Computers \& Mathematics with Applications, 2018.

[13] X. Liang, L. Cheng, Q. Chen, Q. Yang and A. C. To, "A modified method for estimating inherent strains from detailed process simulation for fast residual distortion prediction of single-walled structures fabricated by directed energy deposition," Additive Manufacturing, vol. 23, pp. 471486, 2018.

[14] E. Ponslet and M. Steinzig, "RESIDUAL STRESS MEASUREMENT USING THE HOLE DRILLING METHOD AND LASER SPECKLE INTERFEROMETRY: PART I," Experimental Techniques, vol. 27, no. 3, pp. 43-46, 2003.

[15] E. Ponslet and M. Steinzig, "RESIDUAL STRESS MEASUREMENT USING THE HOLE DRILLING METHOD AND LASER SPECKLE INTERFEROMETRY: PART II," Experimental Techniques, vol. 27, no. 4, pp. 17-21, 2003.

[16] E. Ponslet and M. Steinzig, "RESIDUAL STRESS MEASUREMENT USING THE HOLE DRILLING METHOD AND LASER SPECKLE INTERFEROMETRY: PART III," Experimental Techniques, vol. 27, no. 5, pp. 45-48, 2003.

[17] M. B. Prime and A. T. DeWald, "The Contour Method," in Practical Residual Stress Measurement Methods, doi.org/10.1002/9781118402832.ch5, Wiley Online Library, 2013, p. Chapter 5.

[18] Dassault Systèmes Simulia, ABAQUS User Manual, Providence, RI, USA: version 6.17, 2017.

[19] G. S. Settles, Schlieren and shadowgraph techniques: Visualizing phenomena in transparent media, Berlin: Springer-Verlag, 2001.

[20] Renishaw, 2018. [Online]. Available: http://www.renishaw.com/en/data-sheets-additivemanufacturing--17862.

[21] Innovmetric, 2018. [Online]. Available: https://www.innovmetric.com/en/products/polyworksmodeler. 
[22] Materialise, 2018. [Online]. Available:

http://www.materialise.com/en/software/magics?gclid=CjOKCQiAuP7UBRDiARIsAFpxiRKXLUUy1whO3cA3hA2n7ykbafsTnzlhsux650XUIUFFJKBhwvqSkwaAp7mEALw_wcB.

[23] Sourceforge, 2018. [Online]. Available: https://sourceforge.net/projects/fedes/.

[24] S. M. Afazov, A. A. Becker and T. H. Hyde, "Development of a Finite Element Data Exchange System for chain simulation of manufacturing processes," Advances in Engineering Software, vol. 47, pp. 104-113, 2012.

[25] C. Maranhao and J. P. Davim, "Residual Stresses in Machining Using FEM Analysis - A Review," Rev. Adv. Mater. Sci., vol. 30, pp. 267-272, 2012.

[26] S. M. Afazov, A. A. Becker and T. H. Hyde, "Mathematical Modeling and Implementation of Residual Stress Mapping From Microscale to Macroscale Finite Element Models," Journal of Manufacturing Science and Engineering, vol. 134, 2012. 